\title{
Using Genetic Algorithm to Obtain Optimal Controllers for the DFIG Converters to Enhance Power System Operational Security
}

\author{
João P. A. Vieira, Marcus V. A. Nunes and Ubiratan H. Bezerra \\ Federal University of Pará \\ Brazil
}

\section{Introduction}

The wide spread use of Doubly Fed Induction Generator technology (DFIG) is mostly due to the characteristics of its static converters that permit a variable speed operation with very reduced nominal power requirement which is approximately $25 \%$ of the generator power capacity specification [1-2]. With the increasing number of DFIGs being connected to the electrical grids some instability effects are arising which may worsen the power system security [3]. Time domain simulation techniques have being employed to evaluate the DFIG dynamic behavior and how it is dynamically impacting the power system security [4-7]. These studies are offering a better comprehension of the DFIG intrinsic dynamics when it is connected in electrical power grids, and these studies may be very useful when projecting controllers for this generator.

Recently the particle swarm optimization technique (PSO) has being used to adjust the DFIG controllers gains with the objective of reducing the rotor current and also improving the small-signal stability [8-9]. In both references [8] and [9] the results obtained with the application of the PSO technique are compared with those obtained with a trial and error approach. The Bacteria Foraging optimization method has also being applied to the gain adjustment of the controller that is responsible to improve the damping of the DFIG oscillation modes [10]. However, the characteristics of exhibiting a robust damping and also improving the stability margin may not be guaranteed simultaneously when a change in the operation condition occurs.

This chapter presents a multi-objective optimization methodology based on genetic algorithm (AG) to obtain the controller gains of the rotor side DFIG converter with the main objective of improving the DFIG ride-through capability, the voltage control and the overall power system stability margin.

The methodology in this chapter, combines the GA with the pole placement method, since the gains obtained by the pole placement technique are chosen to compose one of the individuals of the initial population of the GA, in order that the optimal design procedure may start from a good initial solution, which may improve the convergence of the evolutionary procedure towards better solutions. 


\section{DFIG model}

For power system stability studies, the generator may be modeled as an equivalent voltage source behind transient impedance [11]. The differential equations of the stator and rotor circuits of the induction generator with stator current and equivalent voltage behind transient impedance as state variables can be given in a $d-q$ reference frame rotating at synchronous speed. For adequately representing the DFIG dynamics involved in the controllers design the fourth order model of the induction generator is used as presented in [12].

$$
\begin{gathered}
\frac{d \bar{e}_{d}^{\prime}}{d t}=-\frac{1}{T_{o}^{\prime}} \cdot\left[\bar{e}_{d}^{\prime}-\left(\bar{X}-\bar{X}^{\prime}\right) \bar{i}_{q s}\right]+s \omega_{s} \bar{e}_{q}^{\prime}-\omega_{s} \frac{\bar{L}_{m}}{\bar{L}_{r r}} \bar{v}_{q r} \\
\frac{d \bar{e}_{q}^{\prime}}{d t}=-\frac{1}{T_{o}^{\prime}} \cdot\left[\bar{e}_{q}^{\prime}+\left(\bar{X}-\bar{X}^{\prime}\right) \bar{i}_{d s}\right]-s \omega_{s} \bar{e}_{d}^{\prime}+\omega_{s} \frac{\bar{L}_{m}}{\bar{L}_{r r}} \bar{v}_{d r} \\
\frac{\bar{X}^{\prime}}{\omega_{s}} \frac{d \bar{i}_{d s}}{d t}=-\bar{v}_{d s}-\left[\bar{R}_{s}+\frac{\left(\bar{X}-\bar{X}^{\prime}\right)}{\omega_{s} T_{o}^{\prime}}\right] \bar{i}_{d s}+\bar{X}^{\prime} \bar{i}_{q s}+(1-s) \bar{e}_{d}^{\prime}-\frac{1}{T_{o}^{\prime} \omega_{s}} \bar{e}_{q}^{\prime}+\frac{\bar{L}_{m}}{\bar{L}_{r r}} \bar{v}_{d r} \\
\frac{\bar{X}^{\prime}}{\omega_{s}} \frac{\bar{i}_{q s}}{d t}=-\bar{v}_{q s}-\left[\bar{R}_{s}+\frac{\left(\bar{X}-\bar{X}^{\prime}\right)}{\omega_{s} T_{o}^{\prime}}\right] \bar{i}_{q s}-\bar{X}^{\prime} \bar{i}_{d s}+(1-s) \bar{e}_{q}^{\prime}+\frac{1}{T_{o}^{\prime} \omega_{s}} \bar{e}_{d}^{\prime}+\frac{\bar{L}_{m}}{\bar{L}_{r r}} \bar{v}_{q r}
\end{gathered}
$$

Where $X^{\prime}$ and $X$ are respectively the transient reactance and the open circuit reactance; $e_{d}^{\prime}$ and $e_{q}^{\prime}$ are respectively the d-axis and q-axis components of the internal voltage; $T_{o}^{\prime}$ is the open circuit time constant in seconds.

To represent the electrical and mechanical interaction between the electrical generator and wind turbine in transient stability studies, the two masses model is presented, according to [3]:

$$
\begin{gathered}
\frac{d \bar{\omega}_{t}}{d t}=\frac{1}{2 H_{t}}\left(\bar{T}_{m}-K_{s} \delta_{s}\right)-\bar{D}_{t} \bar{\omega}_{t} \\
\frac{d \delta_{s}}{d t}=\omega_{o}\left(\bar{\omega}_{t}-\bar{\omega}_{g}\right) \\
\frac{d \bar{\omega}_{g}}{d t}=\frac{1}{2 H_{g}}\left(K_{s} \delta_{s}-\bar{T}_{e}-\bar{D}_{g} \bar{\omega}_{g}\right)
\end{gathered}
$$

Where $K_{s}$ is the axis stiffness in p.u./rad-elect; $\bar{D}_{t}$ and $\bar{D}_{g}$ are respectively the wind rotor and the electrical rotor damping coefficients; $\omega_{0}$ is the electrical system angular velocity in rad-elect/sec; and $H_{t}$ and $H_{g}$ are the wind turbine and the electrical generator inertia constants respectively, in seconds.

\section{The DFIG converters models}

The model of the converter system includes the representation of the rotor-side converter, the grid-side converter and the dc link and the converter control. The rotor-side and grid- 
side converters are modeled as voltage sources. The control system for the rotor-side converter was implemented so that the field-oriented current control loop is used to control the rotor current, in which the $q$-axis component is responsible for the rotor speed control, and the $d$-axis component controls the terminal voltage, as shown in Fig. 1.

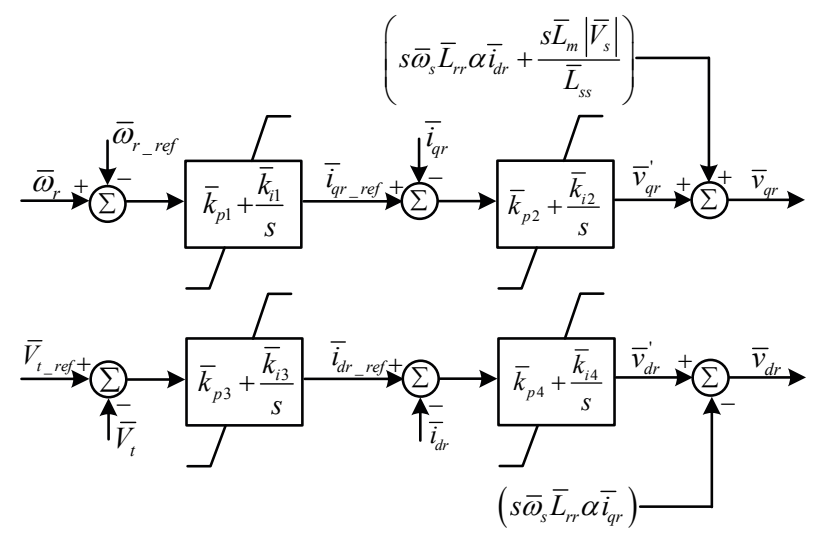

Fig. 1. Rotor-Side Converter Control Scheme

\section{GA-Multi objective optimal control}

The problem of adjusting the controller's gains of the rotor-side DFIG converter, considering a specific operating point, may be formulated as a multi-objective optimization problem. The objectives to be optimized are the absolute errors between the rotor reference currents, which are established by the PI controllers, and the rotor measured currents along the $q$ and $d$ axis respectively and the magnitude of the rotor voltage.

By considering the DFIG vector control formulation as presented in [13], it can be shown that the $q$ and $d$ components of the rotor current are very effective in controlling both the DFIG stator active power and the terminal voltage respectively. This way, improving the rotor current dynamic response (which may be obtained by minimizing the error between the rotor reference and measured currents) may reflect also in a better dynamic performance for the DFIG stator active power and terminal voltage. Besides that, the minimization of an additional term in the objective function that will be responsible for obtaining optimized responses for the magnitude of the rotor voltage may improve the dynamic behavior of other variables which are controlled by the grid side converter, as for example the rotor active power which is a function of the rotor voltage, as well as the dc-link voltage, and the current and reactive power of the grid-side converter.

This way the global objective is to improve the DFIG dynamic behavior after the occurrence of faults in the electrical network enhancing the ride-through capability, voltage control, and also increasing the small-signal and transient stability margins of the power system. A measure that indicates if a good adjustment for the parameters of the rotor side converter has been achieved is given by the fitness function which is composed by the weighted sum of three objectives which will be minimized by the genetic algorithm optimization procedure: 


$$
\bar{F}=\int_{0}^{t s i m}\left(\omega_{1}\left|\bar{i}_{d r_{-} r e f}-\bar{i}_{d r}\right|+\omega_{2}\left|\bar{i}_{q r_{-} r e f}-\bar{i}_{q r}\right|+\omega_{3} \sqrt{\bar{v}_{d r}^{2}+\bar{v}_{q r}^{2}}\right) d t
$$

Where $\omega_{1}, \omega_{2}$ and $\omega_{3}$ are weight factors.

The gains obtained by the pole placement technique as described in [14], form one of the individuals of the GA initial population which may improve the convergence of the GA once the evolutionary process is started with a good initial solution.

\section{Electrical network}

The electrical network used for the simulation studies is a real power system belonging to the COSERN electric power utility that operates in the northeast region of Brazil, in the state of Rio Grande do Norte. In this study, the wind park to be connected is considered as a dynamic equivalent, represented by an equivalent wind generator of $20 \mathrm{MW}$ and $960 \mathrm{~V}$. The wind park must be connected to the distribution electrical grid by $0.96 \mathrm{kV} / 69 \mathrm{kV}$ transformers.

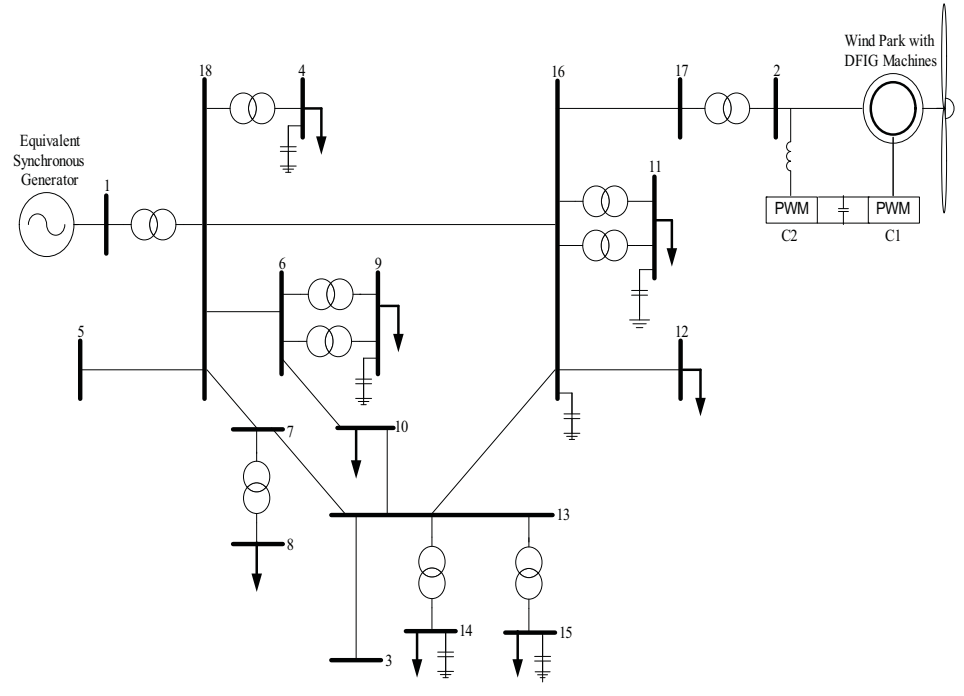

Fig. 2. Electrical Network

\section{Simulations and results}

Firstly, it will be presented the gains obtained for the PI rotor-side controller using the GA optimal design technique. In this optimization procedure a three-phase short circuit was applied at $\mathrm{t}=0.1 \mathrm{~s}$ for $100 \mathrm{~ms}$ at bus 2 . The simulation time was $4 \mathrm{~s}$ and it was considered the base operational condition for the electrical network as shown in Fig. 2, without the "crowbar" protection arrangement.

The gains obtained by the pole placement project and by the GA project are presented in tables 1 and 2, respectively. It may be noticed that the switching frequency used for the CA- 
CC-CA converter system was $2 \mathrm{kHz}$ [15], which is a key parameter for the adjustment of the static converter controls in DFIG generators. The objective function weight factors $\omega_{1}, \omega_{2}$ and $\omega_{3}$ were set equal to 1 .

\begin{tabular}{|c|c|c|c|c|c|c|c|}
\hline$K_{P 1}$ & $K_{I 1}$ & $K_{P 2}$ & $K_{I 2}$ & $K_{P 3}$ & $K_{I 3}$ & $K_{P 4}$ & $K_{I 4}$ \\
\hline-0.27 & -0.016 & 0.4 & 0 & 0.006 & 0.004 & 0.405 & 0 \\
\hline
\end{tabular}

Table 1. Poles Placement Gains Adjustments for the PI Controllers of Rotor-Side Converter

\begin{tabular}{|c|c|c|c|c|c|c|c|}
\hline$K_{P 1}$ & $K_{I 1}$ & $K_{P 2}$ & $K_{I 2}$ & $K_{P 3}$ & $K_{I 3}$ & $K_{P 4}$ & $K_{I 4}$ \\
\hline-0.87 & -0.016 & 0.45 & 7.9 & 0.19 & 0.004 & 0.36 & 0.06 \\
\hline
\end{tabular}

Table 2. GA Gains Adjustments for the PI Controllers of Rotor-Side Converter

To evaluate the performance and robustness of the proposed GA optimization methodology, as well as the effectiveness of the crow-bar protection scheme, three case studies are presented: a) base case load as informed by the electrical utility; b) $20 \%$ load reduction in all load buses with respect to the base case; c) $20 \%$ load increase in all load buses with respect to the base case. In the results presented in this chapter, the optimal design refers to the results obtained by the GA optimization procedure, and formal design refers to the results obtained by the pole placement techniques.

Case a) A three phase short circuit lasting for $100 \mathrm{~ms}$ is applied at $\mathrm{t} 1=1 \mathrm{~s}$, at the end of line $18-16$, near bus 16 . The fault is cleared by the protection scheme and the electrical system changes to a new operational point disconnecting transmission line 18-16.

In Fig. 3 it is shown the transient behavior of the DFIG rotor current. It can be observed that the rotor current limit specified for the rotor-side converter, which is approximately 0.406 p.u., is exceeded right after starting the fault which implies in activating the crow-bar protection, at $\mathrm{t} 2=1.0016 \mathrm{~s}$, by the insertion of external resistances in the DFIG rotor. The inserted resistances reduce significantly the rotor current until the fault is cleared at $\mathrm{t} 3=1.1 \mathrm{~s}$.

It must be emphasized that during the fault period the rotor-side converter remains connected to the DFIG once the rotor current is flowing through the external resistances and not through the converter itself. Immediately after the fault is cleared the crow-bar protection is deactivated and simultaneously the DFIG returns to normal operation, activating again the rotor-side converter controllers.

But when the fault is cleared the rotor current oscillates again as can be seen in Fig. 4. In this case the projected PI controllers, by either pole placement technique or by GA technique, present a good performance in damping the oscillation without the need of activating the crow-bar protection scheme again.

However, it is noticed in Fig. 4 that when using the optimal gains of the GA projected PI controller the rotor current presents a better time response when compared with the pole placement projected PI controller. This improvement is evident in the second oscillation when the current overshoot is higher for the pole placement projected controller, reaching values above 0.3 p.u., as compared with the response obtained by the GA PI controller. Besides that, the GA PI controller reduced more significantly the oscillation after $t=2 \mathrm{~s}$, with respect to the pole placement PI controller. 


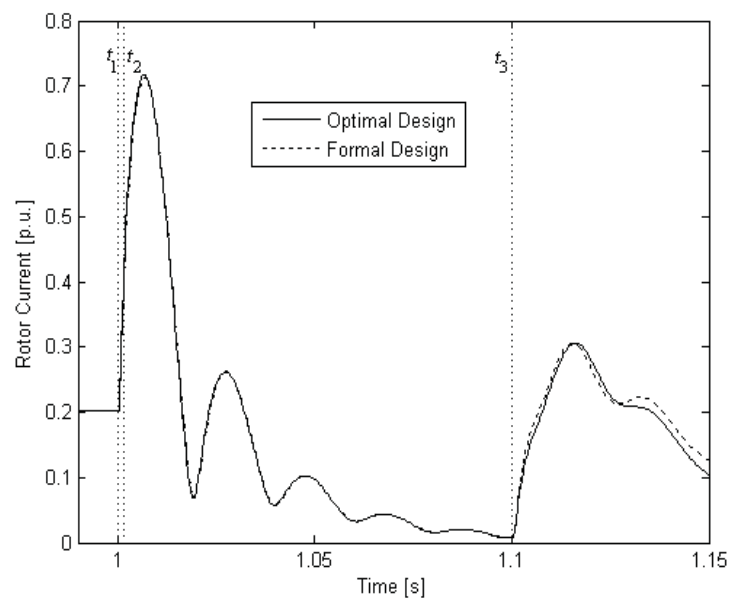

Fig. 3. DFIG Rotor Current

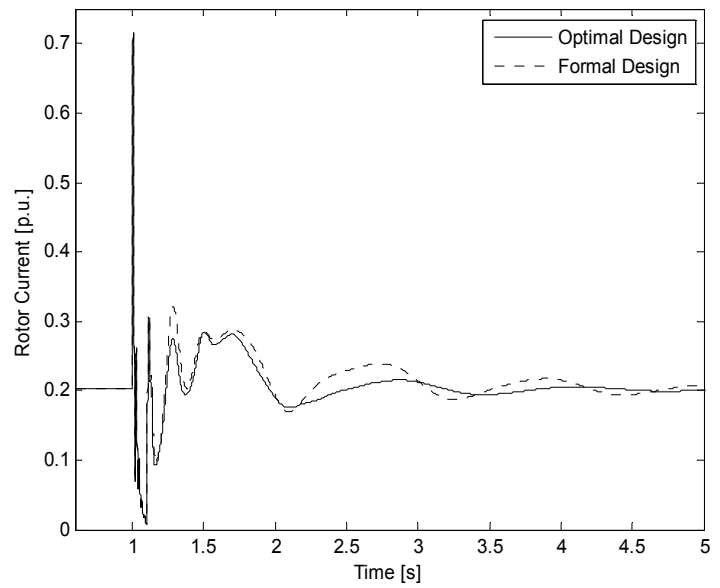

Fig. 4. DFIG Rotor Current

It is shown in Fig. 5 the DFIG rotor voltage. It is observed that the adopted crow-bar protection strategy was efficient, once the rotor voltage oscillation does not exceed the maximum allowed limit value which is specified by the rotor-side converter and is equal to 0.3 p.u. It is noticed also that during the fault the rotor voltage is obtained by the applied voltage to the external resistances of the crow-bar protection scheme, which is equal to the rotor-side converter voltage.

After the fault is cleared, both PI controllers, adjusted by pole placement and by GA techniques, have presented a good performance when submitted to voltage sags. As 


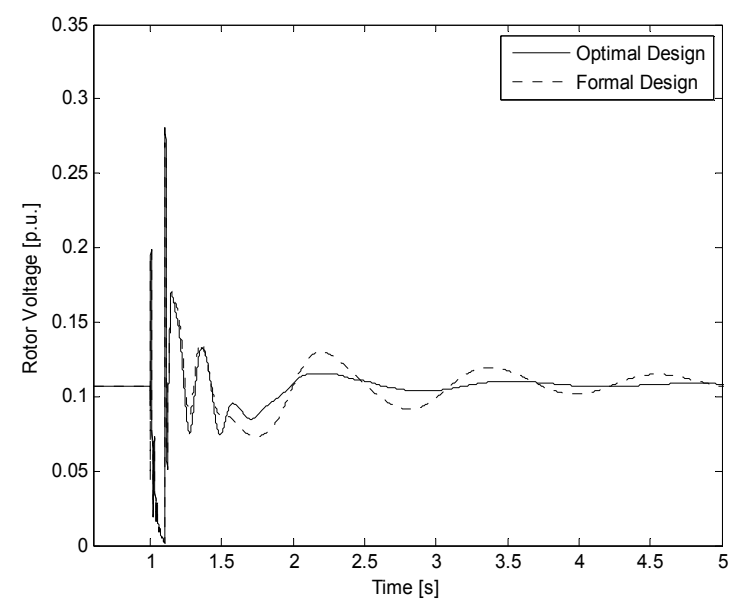

Fig. 5. DFIG Rotor Voltage

observed previously for the current behavior, the optimal PI controller design also reduced the rotor voltage oscillation after $t=2 \mathrm{~s}$, as compared to the PI controller designed by the pole placement technique.

The DC link voltage time responses are shown in Fig. 6, and it can be seen that the response that corresponds to the PI controller projected by the GA technique presents oscillation with lower overshoot and higher damping as compared to the response obtained by the PI controller which gains were adjusted by the pole placement procedure. This is an important aspect to consider since the DC link voltage is one of the variables that may activate the crow-bar protection scheme.

The time response of the DFIG terminal voltage is presented in Fig. 7. It may be observed that by using the GA procedure to project the PI controller, it is obtained for the DFIG terminal voltage a less oscillatory response containing lower overshoot after the fault is cleared, when compared with the PI controller projected by the pole placement technique.

These results are very relevant as much as high voltage values for the wind generator buses may disconnect the DFIG machines by the overvoltage protection scheme. The grid operators in some European countries, for example, are including this recent requisite, known as High Voltage Ride-Through [16], to be attended by wind parks to be connected to the grid.

Besides that, the problem of poorly damped oscillations in distributed generation systems may affect significantly the power quality for the consumers. This happens because such oscillations directly influence the magnitude and frequency of the voltage waveform in load buses.

In Fig. 8 it is presented the plot of the DFIG stator active power. It can be observed a less oscillatory response after the fault is cleared when using the PI controller designed by the GA procedure. The proposed optimization procedure improves the behavior of variables that are decoupled by the vector control strategy employed for the DFIG, namely the terminal voltage (or reactive power) and active power (or rotor speed) as shown in Figs. 7 
and 8 respectively. This way it is justified the methodology of improving the transient behavior of the $\mathrm{d}$ and $\mathrm{q}$ axis components of the rotor current because this improvement has as consequence a better transient behavior for the terminal voltage (or reactive power) and active power (or rotor speed).

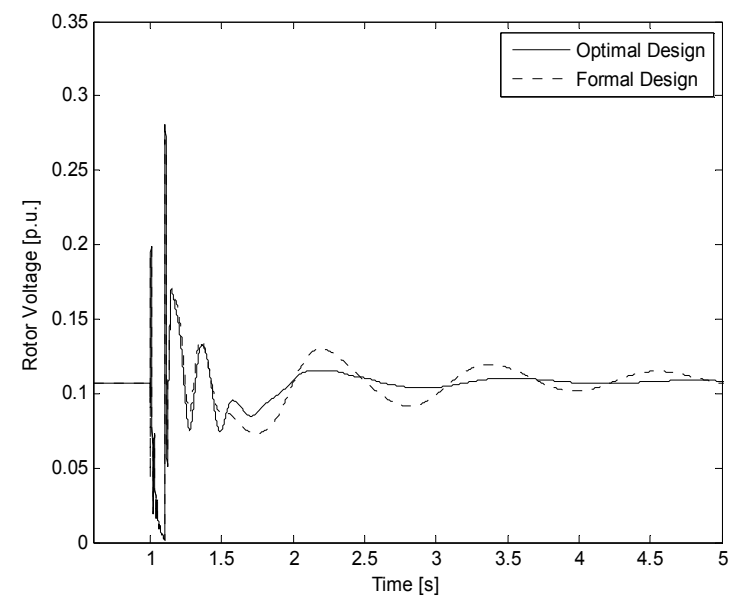

Fig. 6. DC-Link Voltage

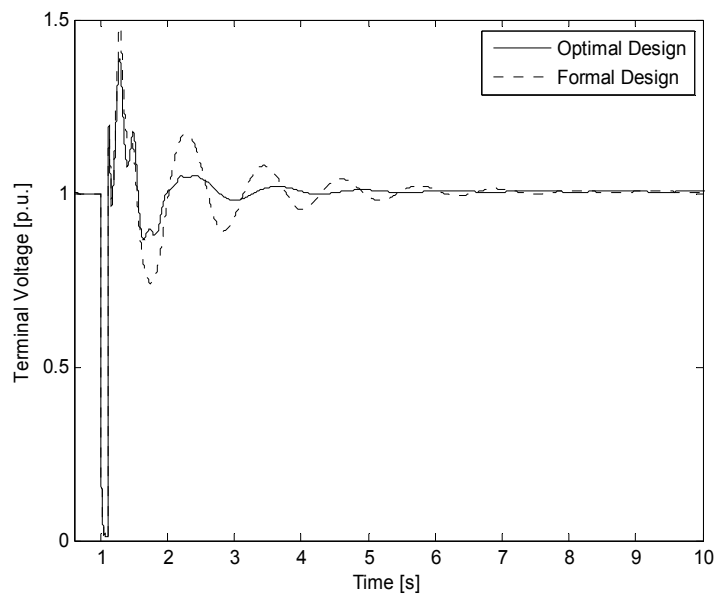

Fig. 7. DFIG Terminal Voltage

Fig. 9 presents the grid-side converter reactive power transient response. It is evident that when the PI controller projected by the GA procedure is used the transient response is less 
oscillatory presenting a better overall performance. The behavior presented by the grid-side converter reactive power, as well as the DC link voltage (which are variables controlled by the grid-side converter) demonstrates the effectivity of the GA optimization procedure in improving the grid-side and rotor-side converters overall performance, although the optimal gain adjustment GA procedure was applied only to the rotor-side controller.

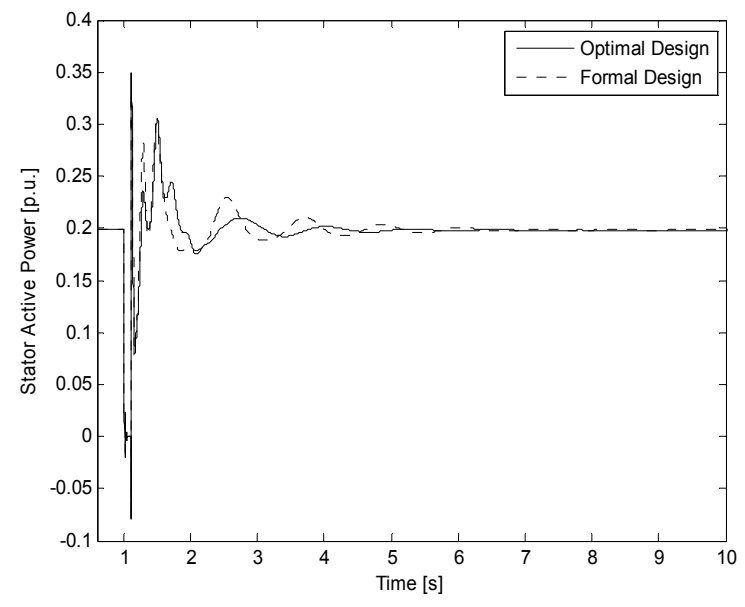

Fig. 8. DFIG Stator Active Power

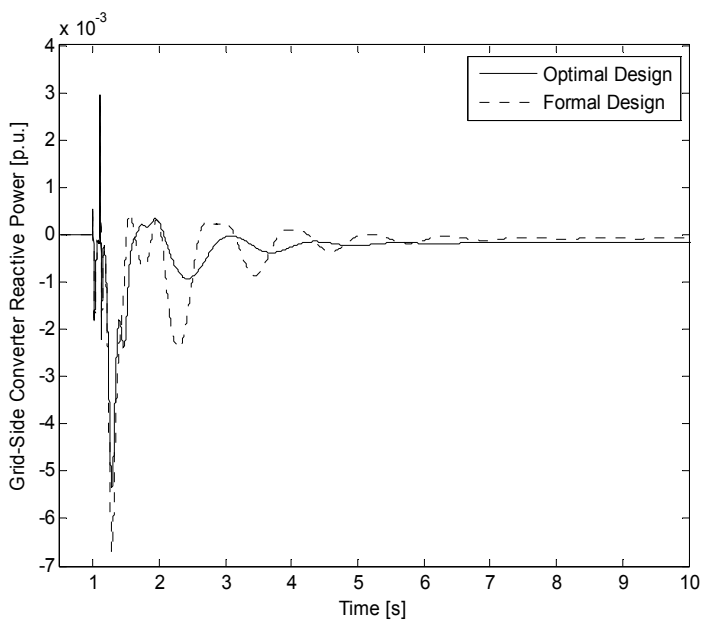

Fig. 9. DFIG Grid-Side Converter Reactive Power 
Fig. 10 presents the rotor angle transient response of the equivalent synchronous generator connected at bus 1 of the Açu electrical system. It is evident that the synchronous generator rotor angle time response is more oscillatory when the PI controller designed by the pole placement procedure is used. In this case the risk of small signal instability is more evident. On the other side, when using the PI controller designed by the GA technique, the low frequency oscillation is reduced which improve the small signal stability margin.

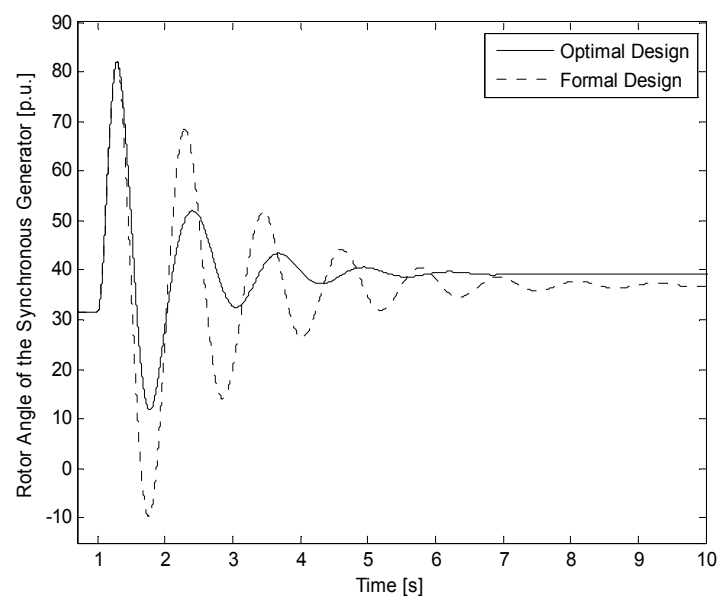

Fig. 10. Rotor Angle of the Synchronous Generator

This way, the proposed GA optimization process to obtain the gains of the DFIG rotor-side converter, besides contributing to a better characteristic of terminal voltage recovery, and ride-though the fault capability, it also improved considerably the system damping characteristic reducing the magnitude of the electromechanical oscillation, without the need of a power system stabilizer (PSS) in the equivalent synchronous generator.

It is worth mentioning that the objective of damping the electromechanical oscillations is not directly included in the GA fitness function. However, the DFIG capacity to introduce damping in the synchronous generator oscillations can be reinforced by an appropriate adjustment of the rotor angle $\delta$, and of the DFIG rotor flux $\bar{\lambda}_{r}$, which are accomplished by the quadrature rotor current component $\bar{i}_{q r}$, that is used in the proposed vector control adopted here, to control the DFIG rotor speed or the active power.

Case b) $20 \%$ load reduction in all buses. A three phase short circuit lasting for $100 \mathrm{~ms}$ at bus 10 is applied.

The time responses of the DFIG variables in this case study are very similar to those presented in Case a. These results presented in Figs. 11 to 15 demonstrate the better performance exhibited by the PI controllers designed by the GA approach, demonstrating robustness and effectiveness when the system operation point is changed. It is observed in Fig. 15 that the rotor angle of the synchronous generator presents smaller low frequency oscillations and a larger transient stability margin, when the PI controller projected by the GA approach is used. 
In this case, the proposed optimal solution contributes: to enhance the DFIG capacity to withstand voltage sags events; to improve voltage control; to increase transient and small signal stability margins, contributing, this way, to improve the overall system security.

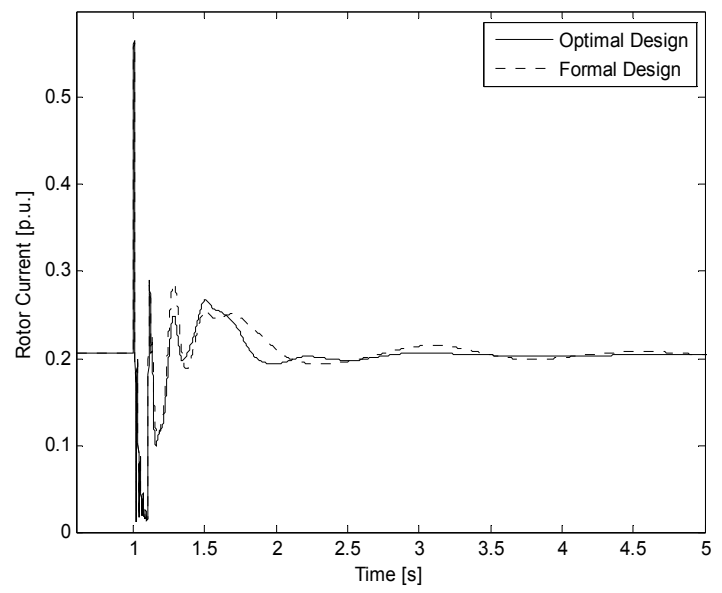

Fig. 11. DFIG Rotor Current

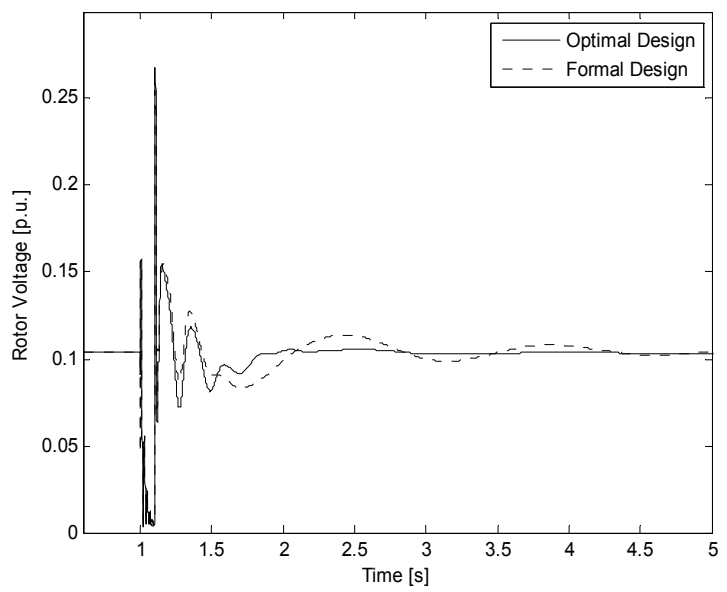

Fig. 12. DFIG Rotor Voltage 


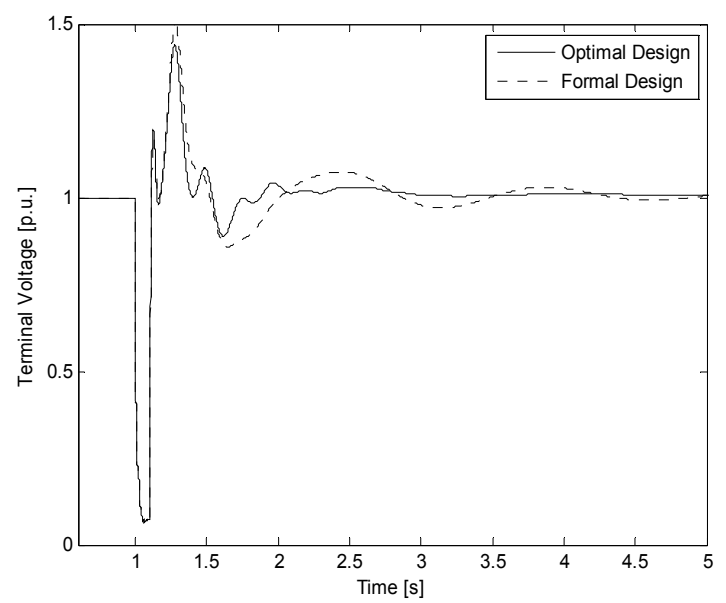

Fig. 13. DFIG Terminal Voltage

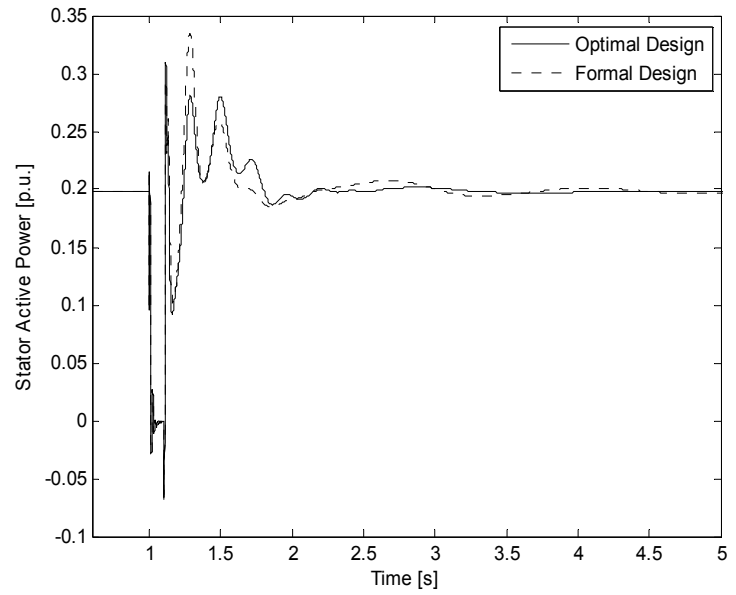

Fig. 14. DFIG Stator Active Power 


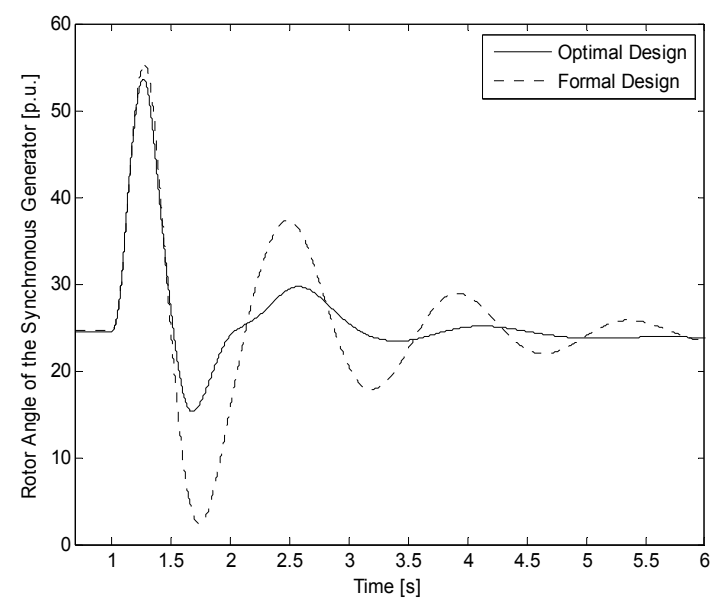

Fig. 15. Rotor Angle of the Synchronous Generator

Case c) 20\% load increase in all buses. A three phase short circuit lasting for $100 \mathrm{~ms}$ at bus 6 is applied.

The DFIG rotor current and rotor voltage time responses are shown in Figs. 16 and 17. It can be seen that immediately after the short circuit is applied the rotor current limit is exceeded, activating the crow-bar protection scheme. After the short circuit is cleared the crow-bar protection is deactivated, and simultaneously the DFIG generators return to normal operation, with the activation of the rotor-side PI controllers.

Just after the fault is cleared both controllers, namely that designed by pole placement and the other by GA, succeeded in maintaining the wind park connected to the grid avoiding the activation of the crow-bar protection, although the PI controller designed by GA procedure was more effective in reducing the rotor voltage and current oscillations in this time period. However, in approximately $\mathrm{t}=2.5 \mathrm{~s}$ it is observed that in the case of using the PI controller projected by the pole placement technique, the converter specified current limit is exceeded again, which activates the crow-bar protection, for a period of $100 \mathrm{~ms}$, which is the transition time imposed by the crow-bar logic.

After this transition time the crow-bar is deactivated and immediately the PI controllers start to function again. However, it may be observed that in the case of using the PI controller designed by the pole placement technique, it was not possible to introduce sufficient damping in the current oscillation and the system became instable.

It is worth noting that the proposed crow-bar protection logic does not allow the activation of the protection scheme for more than two times in a short time period. Besides that, the activation of the crow-bar scheme makes the DFIG machine to operate as a conventional induction machine, lacking the advantage of using the converter control actions.

In Fig. 18 it is presented the DFIG terminal voltage response. When using the PI controller designed by the GA procedure it can be seen an improvement in the terminal voltage control, besides presenting smaller low frequency oscillations, after the fault is cleared. On the other side, when using the PI controller designed by the pole placement technique it was not able to recover the terminal voltage, as can be seen in Fig. 18. 


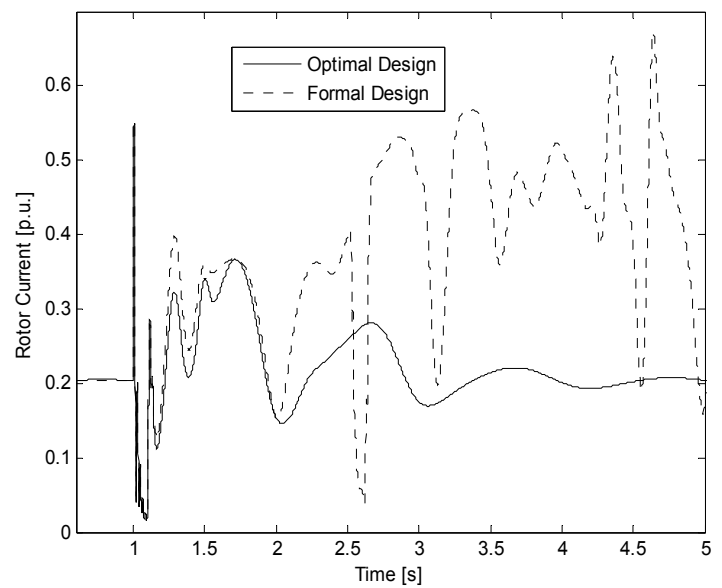

Fig. 16. DFIG Rotor Current

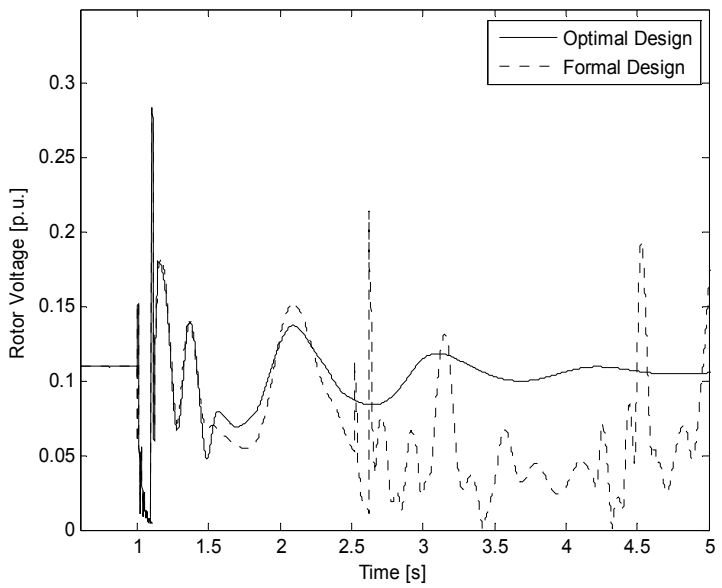

Fig. 17. DFIG Rotor Voltage 


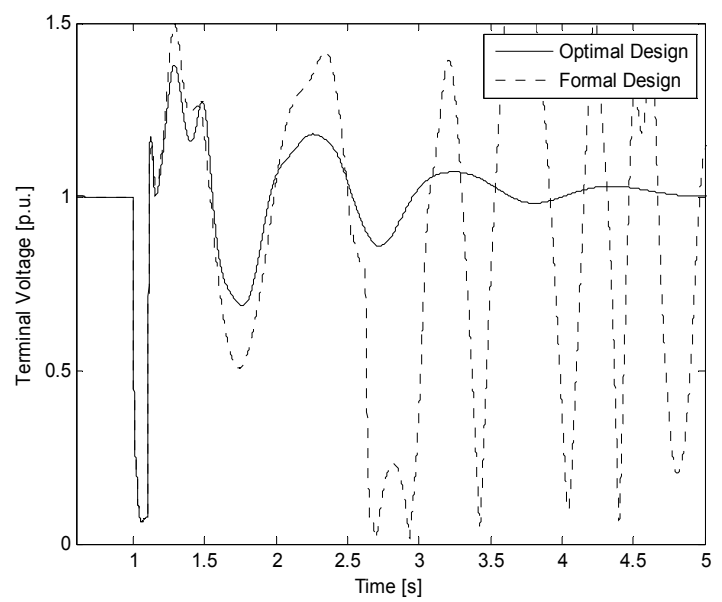

Fig. 18. DFIG Terminal Voltage

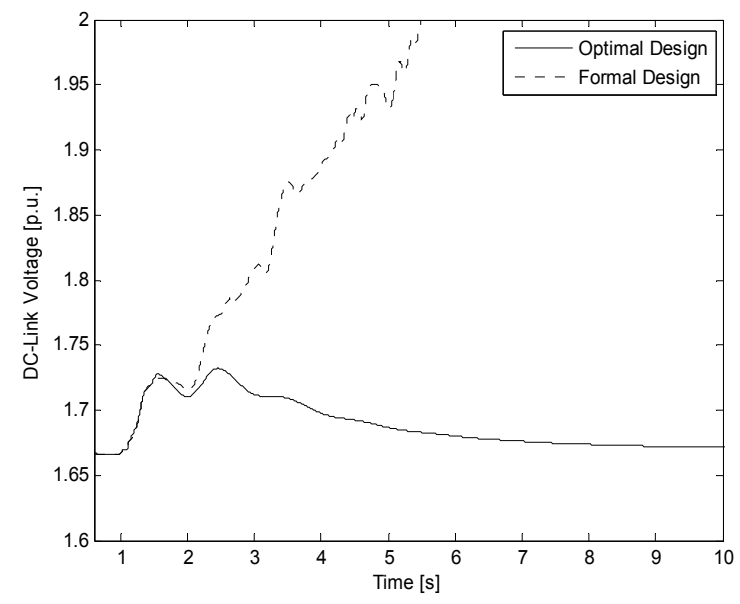

Fig. 19. DC-Link Voltage 
The DC link voltage is shown in Fig.19. When using the controller designed by the pole placement technique it is observed a power unbalance between the grid-side converter and the DFIG rotor, which energy is stored continuously in the capacitor, resulting in increasing voltage and the DC link voltage becomes instable. This behavior is not observed when the PI controller designed by the GA procedure is used, maintaining the DC link voltage stable.

In Fig. 20 it is presented the equivalent synchronous generator rotor angle time response. It can be seen that the synchronous generator looses synchronism in the case the PI controller designed by the pole placement technique is used. The same does not happen when using the PI controller designed by the GA procedure, which maintain the synchronous generator synchronism, besides improving the small signals stability margin.

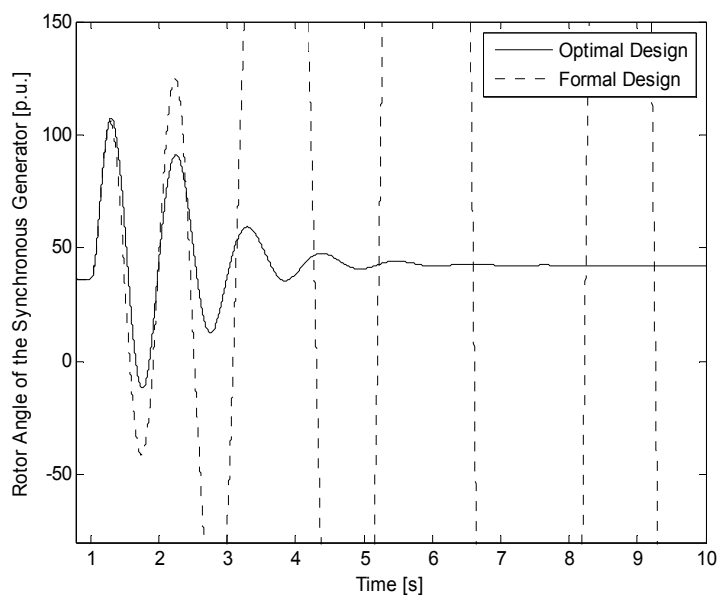

Fig. 20. Rotor Angle of the Synchronous Generator

\section{Conclusion}

This chapter presented a design procedure based on genetic algorithms combined with the formal pole placement methodology to obtain optimal gains for the PI controllers used in the control loop of the DFIG rotor-side converter in order to increase the ride-through capability and the overall stability margin of the power system. The effectiveness of this proposed approach was assessed for the DFIG-based plants using a real electrical network, in three different operational conditions, and the results obtained confirmed the effectiveness of the proposed control design procedure. 


\section{References}

Jenkins N.; Ekanayake J. B.; Holdsworth L. \& Wu X. (2003). Dynamic Modeling of Doubly Fed Induction Generator Wind Turbines. IEEE Transactions on Power Systems. Vol. 18, (May 2003). pp. 803-809,

Muller S.; Deicke M.; \& De Doncker R. W. (2002). Doubly Fed Induction Generator Systems for Wind Turbines. IEEE Industry Applications Magazine. Vol. 8, (May/June 2002) pp. 26-33,

Akhmatov V. (2003). Analysis of Dynamic Behaviour of Electric Power Systems with Large Amount of Wind Power. Ph.D. Dissertation. Tech. University of Denmark, Lyngby, Denmark.

Slootweg J. G. (2003). Wind Power Modelling and Impact on Power Systems Dynamics. Ph.D. dissertation, Delft Univ. Technol, Delft, The Netherlands.

Nunes M. V. A.; Lopes J. A. P.; Zurn H. H.; Bezerra U. H. \& Almeida R. G. (2004). Influence of the Variable-Speed Wind Generators in Transient Stability Margin of the Conventional Generators Integrated in Electrical Grids. IEEE Transactions on Energy Conversion. Vol. 19, No. 4, pp. 692-701,

Mei F. \& Pal B. (2007). Modal Analysis of Grid-Connected Doubly Fed Induction Generators. IEEE Transactions on Energy Conversion, Vol. 22, No. 3, pp. 728-736.

Miao Z.; Fan L.; Osborne D. S. \& Yuvarajan. (2009). Control of DFIG-based Wind Generation to Improve Interarea Oscillation Damping. IEEE Transactions on Energy Conversion. Vol. 24, No. 2. pp.415-422.

Qiao W.; Venayagamoorthy G. K. \& Harley R.G. (2006). Design of Optimal PI Controllers for Doubly Fed Induction Generators Driven by Wind Turbines Using Particle Swarm Optimization. Proc. Int. Joint Conf. on Neural Network, Canada, pp. 1982-1987.

Wu F.; Zhang X. P.; Godfrey K. \& Ju P. (2007). Small Signal Stability Analysis and Optimal Control of a Wind Turbine with Doubly Fed Induction Generator. IET Generation, Transmission \& Distribution. Vol. 1, No. 5. pp. 751-760.

Mishra Y.; Mishra S.; Tripathy M.; Senroy N. \& Dong Z.Y. (2009). Improving Stability of a DFIG based Wind Power System with Tuned Damping Controller. IEEE Transactions on Energy Conversion.

Kundur P.. (1994). Power System Stability and Control. New York. McGraw-Hill.

Mei F. \& Pal B. C. (2008). Modelling of Doubly-fed Induction Generator for Power System Stability Study. Proc. of IEEE PES General Meeting, pp. 1-8.

Pena R.; Clare J. C. \& Asher G. M. (1996). Doubly Fed Induction Generator Using Back-toBack PWM Converters and its Application to Variable Speed Wind-Energy Generation. Proc. Inst. Elect. Eng., Elect. Power Applicat., Vol. 143, No. 3.

Vieira J. P. A.; Nunes M. V. A.; Bezerra U. H. \& Nascimento A. C. (2009). Designing Optimal Controllers for Doubly Fed Induction Generators Using Genetic Algorithm. IET Generation, Transmission \& Distribution, Vol. 3, No. 5, pp. 472-484.

$\mathrm{Xu}$ L. (2008). Coodinated Control of DFIG's Rotor and Grid-Side Converters During Network Unbalance. IEEE Transactions on Power Elect. Vol. 23, pp.1041-1049. 
Feltes C.; Engelhardt S.; Kretschamann J.; Fortmann J.; Koch F. \& Erlich I. (2008). High Voltage Ride-Through of DFIG-based Wind Turbines. IEEE PES General Meeting. Pittsburgh, USA. 


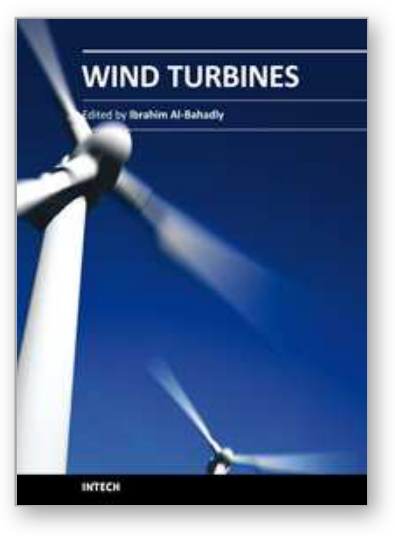

\author{
Wind Turbines \\ Edited by Dr. Ibrahim Al-Bahadly
}

ISBN 978-953-307-221-0

Hard cover, 652 pages

Publisher InTech

Published online 04, April, 2011

Published in print edition April, 2011

The area of wind energy is a rapidly evolving field and an intensive research and development has taken place in the last few years. Therefore, this book aims to provide an up-to-date comprehensive overview of the current status in the field to the research community. The research works presented in this book are divided into three main groups. The first group deals with the different types and design of the wind mills aiming for efficient, reliable and cost effective solutions. The second group deals with works tackling the use of different types of generators for wind energy. The third group is focusing on improvement in the area of control. Each chapter of the book offers detailed information on the related area of its research with the main objectives of the works carried out as well as providing a comprehensive list of references which should provide a rich platform of research to the field.

\title{
How to reference
}

In order to correctly reference this scholarly work, feel free to copy and paste the following:

João P. A. Vieira, Marcus V. A. Nunes and Ubiratan H. Bezerra (2011). Using Genetic Algorithm to Obtain Optimal Controllers for the DFIG Converters to Enhance Power System Operational Security, Wind Turbines, Dr. Ibrahim Al-Bahadly (Ed.), ISBN: 978-953-307-221-0, InTech, Available from:

http://www.intechopen.com/books/wind-turbines/using-genetic-algorithm-to-obtain-optimal-controllers-for-thedfig-converters-to-enhance-power-syste

\section{INTECH}

open science | open minds

\section{InTech Europe}

University Campus STeP Ri

Slavka Krautzeka 83/A

51000 Rijeka, Croatia

Phone: +385 (51) 770447

Fax: +385 (51) 686166

www.intechopen.com

\section{InTech China}

Unit 405, Office Block, Hotel Equatorial Shanghai No.65, Yan An Road (West), Shanghai, 200040, China 中国上海市延安西路65号上海国际贵都大饭店办公楼 405 单元 Phone: +86-21-62489820

Fax: $+86-21-62489821$ 
(C) 2011 The Author(s). Licensee IntechOpen. This chapter is distributed under the terms of the Creative Commons Attribution-NonCommercialShareAlike-3.0 License, which permits use, distribution and reproduction for non-commercial purposes, provided the original is properly cited and derivative works building on this content are distributed under the same license. 